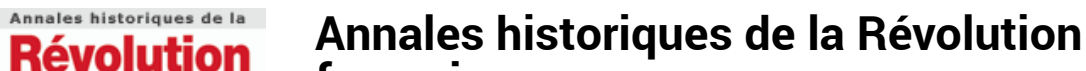

française française

382 | octobre-décembre 2015

Varia

\section{Djoutchi Tougan-Baranovski (1948-2015)}

\section{Varoujean Poghosyan}

\section{OpenEdition}

\section{Journals}

Édition électronique

URL : https://journals.openedition.org/ahrf/13572

DOI : 10.4000/ahrf.13572

ISSN : 1952-403X

Éditeur :

Armand Colin, Société des études robespierristes

\section{Édition imprimée}

Date de publication : 1 décembre 2015

Pagination : 171-172

ISBN : 9782200930028

ISSN : 0003-4436

\section{Référence électronique}

Varoujean Poghosyan, « Djoutchi Tougan-Baranovski (1948-2015) », Annales historiques de la Révolution française [En ligne], 382 I octobre-décembre 2015, mis en ligne le 05 janvier 2016, consulté le 24 avril 2022. URL : http://journals.openedition.org/ahrf/13572 ; DOI : https://doi.org/10.4000/ahrf 13572 
HoMmAGE

DJOUTCHI TOUGAN-BARANOVSKI (1948-2015)

Varoujean POGHOSYAN

Le 5 janvier 2015 est mort à Volgograd Djoutchi Tougan-Baranovski, historien russe spécialiste de l'époque napoléonienne.

Djoutchi Tougan-Baranovski a déployé son activité scientifique et pédagogique dans deux centres de l'enseignement supérieur de Russie, d'abord à l'Université de Saratov, sa ville natale, puis à celle de Volgograd. Après avoir terminé ses études à l'Université de Saratov, il en est devenu l'un des maîtres de conférences. À partir de 1982, il s'est installé à Volgograd et, de 1991 à 2007, y a été titulaire de la chaire d'histoire moderne et contemporaine, bientôt avec le titre de professeur.

Djoutchi Tougan-Baranovski rappelait en maintes occasions sa passion pour l'histoire de Napoléon et de ses maréchaux, en ajoutant que son père le lui avait un jour reproché. C'est sans surprise que, dès le début de son activité scientifique, l'époque napoléonienne se trouva au centre de ses recherches. On lui doit ainsi trois livres sur différents aspects de cette période de l'histoire de France, qui lui ont valu une réputation méritée parmi les historiens soviétiques et russes : Napoléon et les républicains (Saratov, 1980, en russe), Aux origines du bonapartisme (Saratov, 1986, en russe) et Napoléon et le pouvoir. L'époque du Consulat (Balachov, 1993, en russe). J'ai présenté aux lecteurs de notre revue ce dernier livre (AHRF, 1996, n 306, p. 748-749).

Comme presque tous les historiens soviétiques, Djoutchi TouganBaranovski n'a pas eu la possibilité de travailler dans les archives étrangères. Il a pu cependant tirer profit d'éditions françaises - dont des raretés bibliographiques-, conservées dans les bibliothèques russes, ainsi que de sources imprimées publiées par les historiens français. Bien que travaillant hors de Moscou, il gardait des liens étroits avec ses collègues de renom, tels Victor Daline, Anatoli Ado ou Vladlen Sirotkine. Il me racontait souvent ses conversations avec Daline, qu'il considérait comme son maître ; il 
évoquait les conseils et avis que Daline lui avait donnés, tant sur l'époque napoléonienne que sur l'historiographie. Lors de ces conversations, je m'apercevais parfois que Daline m'avait donné les mêmes conseils. TouganBaranovski parlait aussi avec respect d'Anatoli Ado, et il convient de rappeler qu'il prit part avec lui à la publication de la série de La Grande Révolution française : documents et études en six volumes. Il est l'un des coauteurs du quatrième volume sur La bourgeoisie et la Révolution française (Moscou, 1989, en russe), dans lequel il a pris en charge le chapitre « Sur le chemin de Brumaire. La bourgeoisie et la lutte politique en 1797-1799».

Les collègues de Djoutchi Tougan-Baranovski se rappellent d'un professeur attentif, toujours prêt à aider les jeunes historiens ; il a ainsi été très important pour les représentants de ma génération, dont moi-même, en participant notamment à la soutenance de nos thèses sur l'époque révolutionnaire et impériale, soit à Moscou, soit ailleurs.

Au cours des deux dernières décennies, Djoutchi Tougan-Baranovski a rédigé des ouvrages sur l'activité de Mikhaïl Tougan-Baranovski, son grand-père, un intellectuel russe d'origine tatare, qui fut à la fois homme d'État, économiste et historien de la fin du XIX et du début du XX $\mathrm{XX}^{\mathrm{e}}$ siècle. Bien qu'il ait alors été moins présent dans les études napoléoniennes, ses travaux ont marqué la science russe et nous lui en sommes reconnaissants.

Varoujean POGHOSYAN Docteur es sciences historiques Titulaire du Département des études génocidaires Institut d'études arménologiques

Université d'État d'Erevan Varuzhan.poghosyan@mail.ru 